\title{
Bonne nouvelle du désastre et autres poèmes (1980-2004), Leopoldo María Panero
}

\section{Cathy Fourez}

\section{(2) OpenEdition}

1 Journals

Édition électronique

URL : http://journals.openedition.org/agedor/1100

DOI : 10.4000/agedor. 1100

ISSN : 2104-3353

Éditeur

Laboratoire LISAA

Référence électronique

Cathy Fourez, «Bonne nouvelle du désastre et autres poèmes (1980-2004), Leopoldo María Panero », L'Âge d'or [En ligne], 7 | 2014, mis en ligne le 01 mars 2014, consulté le 15 septembre 2020. URL : http://journals.openedition.org/agedor/1100 


\section{Cathy FOUREZ}

Université Charles de Gaulle - LILLE 3, CECILLE (EA 4074)

\section{Bonne nouvelle du désastre et autres poèmes (1980-2004) Leopoldo María Panero}

$\mathrm{Q}$ uelle odeur peut bien avoir la vie lorsque celui qui la vit n'est que la sudation de déchirements nationaux et de brisures familiales, habite un être et une pensée qui ne s'accordent pas avec la partition normative de son époque, sème des baisers d'amour sur des sexes jugés interdits par la morale dominante et égrène des chants de rouges luttes pour ressusciter le sang étouffé de ses amis communistes? «Elle sent mauvais ${ }^{1} »$ dit Panero, elle s'enlise dans toute la fange que pétrit, à discrétion et avec une créativité inouie, le genre humain pour pourrir toute son Humanité. Homme cassé, " mâché $^{2}$ », versifie-t-il, par la répulsion qu'il suscite, Panero est, pour le siècle qui lui revient de vivre, juste une erreur, un accident parce qu'il excède, aux yeux de la société, le bon sens, les codes de conduite, la loi. Il est la chair de ce qui ne peut être accepté parce que tout simplement sa singularité fait de lui un homme incompatible avec les hommes de son temps.

Rien d'étonnant à ce que sa poésie soit la réplique textuelle de l'univers pictural du peintre maniériste, Giuseppe Arcimboldo: comme ce dernier le pratiquait avec les victuailles, la flore et la faune, Panero, lui, débauche les mots, contorsionne la mesure, assemble et ajuste la dissonance pour sombrer dans la majestueuse profondeur du bosselé, du difforme, du nauséeux qu'est l'immonde monde qui le maudit tant. Si le glossaire scatologique accouplé à celui de la vermine et de l'infection entrelace bon nombre de ses compositions, c'est que la parole de l'excrétion, de l'ordure, du résidu, qui participe à l'écroulement de la dignité humaine, dit ce que Panero incarne pour les siens et son pays, à savoir un « $\operatorname{crachat}^{3} »$, un «pus ${ }^{4} »$, un « excrément ${ }^{5} »$ qu'il faut murer parce qu'il n'est que le monstrueux spécimen de la ruine de l'homme.

Orphelin d'un monde incapable de saisir sa propre ignominie et de rencontrer la discordance, Panero vit pleinement, tantôt dans la mélancolie, tantôt dans la détresse, tantôt dans la jubilation, tantôt dans l'auto-dérision, ses hiatus dans les mots. Étant donné que l'épiderme de son réel l'a condamné à "vivre contre la vie », à être « en guerre contre la $v^{6} e^{6}$ ", à faire de son quotidien un "cauchemar atroce ${ }^{7}$ », le poème, loin de constituer un refuge ou un éden, reste, toutefois, une égide pour encore - avant que l'on ne nous l'interdise à tout jamais - rêver un peu, et renoue avec la quête de la vibrante sincérité et de

\footnotetext{
1 Tous les exemples cités sont issus de : Leopoldo María Panero, Bonne nouvelle du désastre et autres poèmes (19802004), traduit de l'espagnol par Victor Martinez et Cédric Demangeot, Éditions Fissile, Montpellier, 2013 / « Héroïne », p. 30.

2 « Des fous », p. 32.

3 « oh exister comme un crachat», in « Peeping Tom», p. 161.

4 «Le poème comme un pus / comme le cri de mes yeux », in « Des fous II », p. 39.

5 « (...) la merde de la vie / et la merde est l'unique vérité », in «Life studies », p. 109.

${ }^{6}$ « La condamnation », p. 147.

${ }^{7}$ « le cauchemar atroce de vivre, / de vivre sans rêve, sans appui », in « Danse de la mort », p. 150.
} 
la cruelle authenticité, les seules à même de reconnaître que l'Humanité sera, lorsque l'homme ne sera définitivement plus ${ }^{8}$.

Avec une émotion enfantine, une mise en bouche écorchée, une âme douloureusement entaillée, Panero rit et pleure le visage hideux de notre passé proche et de notre actualité, et é-crit que la folie ne loge pas forcément là où on l'a mise sous clef, mais occupe, sans aucun doute, les organes vitaux du prétendu progrès, et donc des civilisations.

L'écrivain chilien Roberto Bolaño, qui tout au long de son œuvre narrative, a exploré la barbarie de ces 100 dernières années, avait découvert en Panero - qu'il décline dans bon nombre de ses romans comme une figure de proue, un fil conducteur, une courroie de transmission - une lecture prodigieuse pour explorer la fabrique par l'homme de l'inhumanité, et pour questionner le sens de notre indifférence croissante à la vue de l'humiliation et la chute de l'autre. Son livre posthume, 2666 - qui met en lumière, à la frontière mexico-étasunienne, le statut du corps de la femme perçu comme un moyen de communication, un champ de bataille, un défouloir et un territoire conquis -, s'est probablement nourri de ce micro-poème de Panero qui traduit tout le vide qui nous entoure pour penser autrement l'être humain qui ne pense qu'à s'entredévorer : "Ailes, battement contre le rien/ où le désert est une fleur / une fleur qui déteste l'homme / et se nourrit de morceaux d'être" $»$.

Vendredi 31 mai $2013^{10}$

\footnotetext{
8 «(...) cherche l'immonde secret de la vie / parce qu'il n’y a pas d'autre mal que la vie/ jusqu'à ce que la mort nous change en hommes », in «Danse de la mort », p. 146.

9 «Cannibale », p. 198.

10 Texte écrit par Cathy Fourez lors de la présentation de l'ouvrage Bonne nouvelle du désastre et autres poèmes (1980-2004), traduit de l'espagnol par Victor Martinez et Cédric Demangeot, mai 2013, Librairie VO, librairie internationale de Lille.
} 